\title{
Team learning and context; assessing the relationship between team-learning activities and contextual factors of team-learning environment and team-configurations
}

\author{
This article was published in the following Dove Press journal: \\ Nursing: Research and Reviews \\ 7 October 2011 \\ Number of times this article has been viewed
}

\section{Olaf Timmermans' \\ Roland Van Linge ${ }^{2}$ \\ Peter Van Petegem ${ }^{3}$ \\ Joke Denekens ${ }^{4}$}

'Faculty of Medicine, Nursing and Midwifery Science, University of Antwerp, Belgium; ${ }^{2}$ University Medical Centre Utrecht, Department of Nursing Sciences, Utrecht University, The Netherlands; ${ }^{3}$ Institute of Education and Information Sciences, University of Antwerp, Belgium; ${ }^{4}$ Department General Practice, University of Antwerp, Belgium
Correspondence: Olaf Timmermans University of Antwerp, Faculty of Medicine, Nursing and Midwifery Science, Universiteitsplein I, 26I0 Wilrijk, Belgium Tel +3232662504

$\mathrm{Fax}+3232662501$

Email olaf.timmermans@ua.ac.be
Background: The prevalence of team-learning activities in nursing teams is influenced by contextual factors. Although team learning is important for nursing teams to perform, there is a paucity of research exploring the relationship between team-learning activities and contextual factors in nursing teams. The aim of this study was to study the relationship between team learning and contextual factors of the nursing team.

Methodology: Correlation and multiple regression analyses were used to study the relationship between team learning and five contextual variables. One contextual variable represented the overall environment for learning, and the other four contextual variables characterized basic configurations of organizational characteristics of nursing teams. An interrelation between the contextual variables was expected, so multiple regression models were tested for multicollinearity by regression commonality analysis to detect unique and common contributions of each independent variable.

Findings: Results of this study indicate that team-learning activities in nursing teams can be enhanced by contextual factors such as: (1) strengthening stimulation of the psychological safety, (2) openness, (3) shared goals, and (4) an open, external-oriented view. Multiple regressions yielded three models that explain $76 \%, 81 \%$, and $83 \%$ of the variance in team learning. Commonality analyses showed the importance of interrelationships between the contextual factors.

Practical implications: Nurses undertake team-learning activities to process information needed to perform production-oriented and innovation-oriented tasks. Contextual variables affect the prevalence of team-learning activities in nursing teams. To enhance team learning in nursing teams, management and nurses should strengthen the facilitation of a development oriented team configuration and an intense team-learning environment.

Keywords: team learning, nursing, contextual factors

\section{Introduction}

As in other businesses, nursing teams are transforming from production-oriented teams towards ambidextrous teams; teams that simultaneously produce and innovate. ${ }^{1-3}$ In origin, health care organizations set up nursing teams because of their expected influence on production-oriented processes. ${ }^{1,4}$ Nursing teams were established to produce nursing care to a specific population, such as a clinical nursing team on a surgery ward with the function to provide nursing care to patients that undergo surgery, or to provide education in nursing schools. Currently, nursing teams are also expected to adapt to changes by modifying themselves to keep pace with the continuous changes 
in their specific nursing care or in the structures in which they provide the care. ${ }^{5-7}$ Teams in nursing are becoming ambidextrous, as they have to be productive and at the same time have to develop the nursing care or education they provide. Ambidextrous teams have the ability to simultaneously manage both production-oriented and development-oriented processes. ${ }^{8}$ This ambidextrous function causes a continuity of different team-learning activities in the nursing team. ${ }^{5,6,9}$ In the workplace, nurses need information to execute the production-oriented as well as innovation-oriented tasks. ${ }^{1,3}$ To process needed information, nurses in teams can undertake team-learning activities like listening to each other's ideas, giving and taking feedback, or challenge one another for new viewpoints on specific matters in the nursing team. ${ }^{10}$

\section{Key points}

- Nurses undertake team-learning activities to gather, process, and store the information that is needed to perform production-oriented and innovation-oriented tasks.

- Different contextual variables form a specific context for nursing teams that hinders or facilitates team learning.

- Team-learning activities in nursing teams can be enhanced by strengthening stimulation of the psychological safety, openness, shared goals, and an open, external-oriented view.

Team learning in ambidextrous teams was first mentioned by Kang and Snell, who suggested that production- and development-oriented processes in teams create productionoriented and development-oriented team learning processes. ${ }^{11}$ Each team learning process has its own type of information, challenging nurses in teams to perform a variety of team-learning activities. In daily practice, nurses in teams simultaneously undertake team-learning activities that lead to production-oriented as well as development-oriented team learning. ${ }^{11-14}$ Production-oriented team learning is triggered by information needed for the production processes the team stands for and results in actual production of nursing care or education. ${ }^{11,15}$ Development-oriented team learning is rooted in the incongruence between current practice and professional or societal developments. Development-oriented team learning results in radical changes in the way the nursing teams provide their nursing care or nursing education. ${ }^{12,16}$

The concepts of production- and development-oriented team learning are in unison with the theoretical concepts of first- and second-order learning in organizations, wherein productive and developmental learning are defined as adaptive and transformational learning. ${ }^{10,15}$ In nursing teams, team learning is identified in five factors that clustered team-learning activities; two factors are related to the gathering of information, one factor to the processing of information, and two factors are related to the storage and retrieval of information. The factors representing gathering information and storage of information differed on information used for production-oriented processes, or information used for developmental-oriented processes in the team which reflected today's ambidextrous character of nursing teams. ${ }^{10}$

Nursing teams exist in a variety of settings, such as university hospitals, mental health, community hospitals, or nursing schools. They differ in function, composition, and contextual factors as team-learning environments or the teams' culture. ${ }^{17}$ Edmondson et $\mathrm{al}^{18}$ introduced psychological safety in the team as a contextual factor for team learning. Psychological safety was defined as the shared belief that the team is safe for interpersonal risk taking. ${ }^{18}$ Team-learning activities like exchanging feedback and listening to each other demand an open attitude and vulnerability from the nurses in the team. Therefore, psychological safety within the team is essential to exploit team-learning activities. ${ }^{16,19,20}$ Van Wetten et $\mathrm{al}^{20}$ constructed an overall contextual factor denoted "teamlearning environment." In addition to reflecting Edmondson et al's ${ }^{18}$ earlier work on psychological safety, the team-learning environment concept included shared goals within the team, positive teamwork attitudes, and openness. ${ }^{20}$

In addition to the team-learning environment in the team, team learning is supported by an external focus of the nursing team: tracking information and developments from outside the team and exploring their use within the team. ${ }^{7,16}$ Van Linge $^{7}$ defined such nursing teams as teams with a development-oriented configuration. Based on the theoretical work of Scheinn, ${ }^{21}$ Van Linge delineated six team characteristics over two different dimensions (internal vs external focus and control vs flexibility) at the operational level, the level of espoused values, and the level of basic underlying assumptions of teams. ${ }^{7,21,22}$ Consequently, four basic team configurations for nursing teams were constructed: the regulation-oriented team configuration, which aims to formalize processes and standards; the goal-oriented team configuration, which is characterized by the formalization of goals and targets for results; the team-oriented team configuration, which highlights the importance of cooperation, consensus, and fine-tuning; and the development-oriented 
team configuration, which focuses on flexibility, external focus, creativity, and autonomy. ${ }^{7}$

The literature does not include a study addressing team learning and contextual factors in nursing teams. Therefore, the aim was to study the relationship between team learning, team-learning environment, and the configuration of teams' organizational characteristics in 79 nursing teams. The literature on team learning and contextual factors led us to the following hypotheses:

Hypothesis 1: The contextual variables, team-learning environment, team-oriented team configuration, and development-oriented team configuration, have a positive effect on the prevalence of team-learning activities in nursing teams.

Hypothesis 2: The contextual variables, goal-oriented team configuration and regulation-oriented team configuration, have a negative effect on the prevalence of teamlearning activities in nursing teams.

\section{Methods}

In a cross-sectional design, self-reported data were gathered from individual members of nursing teams. Using a structured questionnaire that included team learning and context items, data were collected between November 2008 and March 2009. In meetings with the nursing teams, the researcher or a trained research nurse distributed the questionnaire packet after explaining the rationale for the study. To increase the response rate in 24-hour nursing teams, either the nurse researcher returned frequently, or a staff nurse was instructed to distribute the questionnaire to nurses not present at the meeting. Convenience sampling yielded data from 1111 individual responders, representing 79 nursing teams from mental health facilities (32\%), general hospitals (27\%), university hospitals $(27 \%)$, and nursing education (14\%) (Table 1). All teams originated in health care organizations and Bachelor of Nursing schools in the Netherlands and Belgium, and participated in an academic service partnership on learning and innovation in nursing.
Individual team members voluntarily cooperated to support the research project and signed an informed consent form. Included were responders who were members of a nursing team for 6 months or more. Excluded were students and untrained nursing staff. Included in the analysis were nursing teams wherein a minimum of $80 \%$ of the individual members were nurse educated. Excluded from analyses were individual cases with an item nonresponse rate greater than $10 \%(n=1)$. Also, teams with a response rate of less than $60 \%$ of their members $(n=0)$ were excluded for analysis. Random missing data on items were replaced by the scale mean; $0.06 \%$ of the data were entered this way. ${ }^{23}$ To ensure confidentiality, the returned questionnaires were coded before being entered into the database. ${ }^{24}$ Approval from the research committee of the academic service partnership was obtained for the study.

\section{Instruments}

Team learning was measured using the revisited teamlearning scale for nursing teams. ${ }^{10}$ This scale was developed in Dutch and contains 26 items on team-learning activities, divided over five subscales. The subscale pertaining to processing information contains nine items (Cronbach's alpha $[\alpha] 0.94)$ representing the actual interpretation and application of information in the team. Two subscales containing four items refer to the gathering ( $\alpha 0.86)$, and four items refer to the storage or reuse $(\alpha 0.87)$ of information used for production-oriented processes in the nursing team. In addition, two subscales with five items refer to the gathering $(\alpha 0.86)$ and four items to the storage or reuse $(\alpha 0.83)$ of development-oriented information. Nurses used this instrument to indicate their perception of team-learning behaviors in their team. All 26 items were rated on a Likert scale ranging from 1 ("never") to 5 ("very often").

In this study, context was defined as the "team-learning environment" and the "team configuration".7,20 Teamlearning environment was assessed using a twelve-item

Table I Descriptive statistics of the study population

\begin{tabular}{|c|c|c|c|c|c|}
\hline$(\mathbf{N}=79)$ & Total & $\begin{array}{l}\text { Mental } \\
\text { health }\end{array}$ & $\begin{array}{l}\text { Community } \\
\text { hospital }\end{array}$ & $\begin{array}{l}\text { University } \\
\text { hospital }\end{array}$ & $\begin{array}{l}\text { Nursing } \\
\text { education }\end{array}$ \\
\hline Setting (\%) & 100 & 32 & 27 & 27 & 14 \\
\hline Team size in $N(M, S D)$ & $17(8.0)$ & $13(5.0)$ & $14(5.2)$ & $15(7.1)$ & $23(8.6)$ \\
\hline Percentage bachelor-level nurses in team $(M, S D)$ & $50.6(28.4)$ & $42.2(18.9)$ & $40.4(13.8)$ & $63.8(12.3)$ & $81.1(9.9)$ \\
\hline Percentage diploma degree nurses in team $(M, S D)$ & $41.2(18.3)$ & $39.7(5.0)$ & $5 \mathrm{I} . \mathrm{I}(5.0)$ & $33.9(5.0)$ & 0 \\
\hline Percentage non-nurse educated team members $(M, S D)$ & $8.2(11.5)$ & I8.1 $(6,2)$ & $8.5(10.3)$ & $2.3(3.8)$ & $19(4.9)$ \\
\hline Percentage 24 hours nursing care teams $(M, S D)$ & $64(14.6)$ & $83(6.2)$ & $74(18.5)$ & $92(4.8)$ & 0 \\
\hline Age team members $(M, S D)$ & $50.6(28.4)$ & $42.2(18.9)$ & $20.4(13.8)$ & $83.8(12.3)$ & $61.1(9.9)$ \\
\hline Years of clinical experience team members $(M, S D)$ & $13.9(5.2)$ & II.I (3.8) & $14.3(6.0)$ & $15.8(4.0)$ & $9.3(2.5)$ \\
\hline
\end{tabular}

Abbreviations: $M$, mean; SD, standard deviation. 
questionnaire $(\alpha 0.96)$ constructed by Van Wetten et al. ${ }^{20}$ The questions represented were three items on shared goals, two items on positive attitude towards teamwork, four items on psychological safety, and two items on openness. Items were stated as "in my team, we share the same goals," or "in my team, I feel safe." All items were rated on a Likert scale ranging from 1 ("never") to 5 ("very often").

Team configuration was measured using the 24-item observed team configuration scale of Van Linge. ${ }^{7}$ This instrument represents the four basic team configurations as defined by Van Linge using four subscales with six items $\operatorname{each}^{7,21,22}$ : (1) the regulation-oriented team configuration $(\alpha$ $0.87)$, (2) the goal-oriented team configuration ( $\alpha 0.76),(3)$ the team-oriented team configuration ( $\alpha 0.91)$, and (4) the development-oriented team configuration ( $\alpha$ 0.89). For example, an item in the regulation-oriented team configuration subscale was stated as "in my team, communication is based on protocols," and an item in the development-oriented team configuration subscale was stated as "in my team, communication is based on general principles and norms." All items were rated on a Likert scale ranging from 1 ("never") to 5 ("very often").

\section{Data aggregation}

Where the constructs of team learning and context were seen as shared team properties, data were aggregated from the individual to the team level. ${ }^{25}$ All 1111 individual cases were aggregated to 79 teams-level cases, by taking the sum of the mean scores of all items to compute the scales and subscales. ${ }^{25,26}$ Within-group agreement and homogeneity of individual level data were tested before aggregation..$^{25,27}$ The intraclass correlation (ICC) analyses of the team learning and context variables used in this study resulted in ICC1 values between 0.11 and 0.19 . Analyses of ICC2 resulted in values between 0.72 and 0.79 . The results of these analyses legitimized the aggregation to team-level variables. $^{25,28}$

\section{Data analyses}

Data analyses were completed using SPSS (v 16.0; SPSS Inc, Chicago, IL). Statistics were generated to summarize teamlearning and team context variables. We used the subscales, as well as the overall 26-item scale of the revisited team-learning scale for nursing teams to explore relationships between team-learning and contextual variables using Pearson's product-moment correlation coefficient. ${ }^{24}$ In congruence with Van Woerkom and Croon, ${ }^{22}$ all hypotheses concerning the relationship between team-learning and contextual variables were tested simultaneously in a hierarchical multiple regression model with the overall 26-item scale of the revisited team-learning scale for nursing teams as a dependent variable. Due to the theoretical interrelation between all included variables, the regression models were tested for multicollinearity with the tolerance test and the variance inflation factor (VIF). Also, we added a regression commonality analysis to supply the unique and common contribution of each independent variable to the regression. ${ }^{29}$ All tests were conducted at a $5 \%$ level of significance.

\section{Results}

Table 2 presents mean score $(M)$, standard deviation (SD), percentage of maximum score, Pearson's product-moment correlation coefficient, and Cronbach's alpha $(\alpha)$ of the team learning and context variables. We detected high mean scores for the subscales storage and retrieval production-oriented information $(M=14.7$; SD $=1.6)$ and for processing information $(M=29.0 ; \mathrm{SD}=3.1)$. In contrast, for the subscales related to gathering information, we detected low mean scores. All team learning variables showed moderate-tostrong interrelationships.

The correlation matrix in Table 2 shows moderate-tostrong relationships between all team-learning and context variables. Pearson's product-moment correlation coefficient varied between 0.324 and 0.870 . The overall 26-item teamlearning scale was positively related with the developmentoriented configuration, the team-oriented configuration, and the team-learning environment. The team-learning environment was moderately positively related with the regulationoriented and goal-oriented configuration. The team-learning environment was positively related with the team-oriented and development-oriented team configuration. Only the gathering professional-oriented information subscale showed low correlation coefficients with all contextual factor variables in this study. Strong relationships were detected between team-learning environment, and the team-oriented and development-oriented configurations.

Univariate linear regression analyses with the 26-item team-learning scale team as the dependent variable showed associations with the development-oriented team configuration $(\beta=0.759 ; P=0.001)$, the team oriented configuration ( $\beta=0.762 ; P=0.007)$ and the team learning environment $(\beta=0.722 ; P=0.000)$.

Multiple regression analyses discriminated three models (Models 1, 2, and 3) that explain 75\%,81\%, and 83\%, respectively, of the variance in team learning. Model $1(P=0.001)$ explains $75 \%$ of the variance in team learning and includes 
Table 2 Mean score, standard deviation, percentage of maximum score, Pearson's product-moment correlation coefficient, and Cronbach's $\alpha$ of all team-learning and context variables

\begin{tabular}{|c|c|c|c|c|c|c|c|c|c|c|c|}
\hline & I & 2 & 3 & 4 & 5 & 6 & 7 & 8 & 9 & 10 & 11 \\
\hline I Team learning & $0.93^{\mathrm{a}}$ & & & & & & & & & & \\
\hline $\begin{array}{l}2 \text { Gathering } \\
\text { production-oriented } \\
\text { information }\end{array}$ & $0.727^{b}$ & $0.87^{\mathrm{a}}$ & & & & & & & & & \\
\hline $\begin{array}{l}3 \text { Gathering } \\
\text { development-oriented } \\
\text { information }\end{array}$ & $0.593^{b}$ & $0.685^{* *}$ & $0.86^{\mathrm{a}}$ & & & & & & & & \\
\hline 4 Processing information & $0.743^{\mathrm{b}}$ & $0.584 * *$ & $0.484 * *$ & $0.95^{\mathrm{a}}$ & & & & & & & \\
\hline $\begin{array}{l}5 \text { Storage and retrieval } \\
\text { of production-oriented } \\
\text { information }\end{array}$ & $0.716^{b}$ & $0.588^{* *}$ & $0.464 * *$ & $0.680 * *$ & $0.87^{\mathrm{a}}$ & & & & & & \\
\hline $\begin{array}{l}6 \text { Storage and retrieval } \\
\text { of development-oriented } \\
\text { information }\end{array}$ & $0.723^{b}$ & $0.592 * *$ & $0.486 * *$ & $0.679 * *$ & $0.587^{* *}$ & $0.83^{\mathrm{a}}$ & & & & & \\
\hline $\begin{array}{l}7 \text { Team-learning } \\
\text { environment }\end{array}$ & $0.850 * *$ & $0.637^{* *}$ & $0.514 * *$ & $0.886 * *$ & $0.710^{* *}$ & $0.557^{* *}$ & $0.96^{\mathrm{a}}$ & & & & \\
\hline $\begin{array}{l}8 \text { Regulation-oriented } \\
\text { configuration }\end{array}$ & $0.658^{* *}$ & $0.400 * *$ & $0.346 * *$ & $0.595 * *$ & $0.557^{* *}$ & $0.737^{* *}$ & $0.499 * *$ & $0.87^{\mathrm{a}}$ & & & \\
\hline $\begin{array}{l}9 \text { Goal-oriented } \\
\text { configuration }\end{array}$ & $0.690^{* *}$ & $0.537^{* *}$ & $0.466 * *$ & $0.596 * *$ & $0.528 * *$ & $0.694 * *$ & $0.538 * *$ & $0.737^{* *}$ & $0.76^{\mathrm{a}}$ & & \\
\hline $\begin{array}{l}10 \text { Team-oriented } \\
\text { configuration }\end{array}$ & $0.852^{* *}$ & $0.625^{* *}$ & $0.449 * *$ & $0.861 * *$ & $0.769 * *$ & $0.632 * *$ & $0.891 * *$ & $0.588 * *$ & $0.630 * *$ & $0.91^{\mathrm{a}}$ & \\
\hline $\begin{array}{l}\text { II Development-oriented } \\
\text { configuration }\end{array}$ & $0.87 I^{* *}$ & $0.704 * *$ & $0.557 * *$ & $0.829 * *$ & $0.699 * *$ & $0.698 * *$ & $0.829 * *$ & $0.675^{* *}$ & $0.763 * *$ & $0.892 * *$ & $0.89^{a}$ \\
\hline Possible scale score & $26-130$ & $5-30$ & $4-20$ & $9-45$ & $4-20$ & $4-20$ & $11-55$ & $6-30$ & $6-30$ & $6-30$ & $6-30$ \\
\hline Mean & 81.2 & 10.7 & 14.6 & 29.0 & 14.7 & 12.1 & 40.5 & 19.4 & 19.1 & 21.6 & 19.8 \\
\hline SD & 7.4 & I.I & 1.6 & 3.1 & 1.6 & 1.5 & 4.2 & 2.1 & 1.7 & 2.0 & 1.9 \\
\hline Minimum score & 64.1 & 8.7 & 10.8 & 22.3 & 9.6 & 8.9 & 31.9 & 15.6 & 14.7 & 16.1 & 15.0 \\
\hline Maximum score & 96.5 & 13.1 & 18.8 & 35.7 & 17.8 & 15.7 & 51.0 & 24.0 & 22.5 & 24.7 & 24.0 \\
\hline
\end{tabular}

Notes: aCronbach's $\alpha$; 'borrected item total correlation; **P $<0.001$.

Abbreviation: SD, standard deviation.

only the variable 'development-oriented configuration' $(\beta=0.871 ; P=0.000)$ (Table 3).

Model 2 explains $81 \%(P=0.005)$ of the variance in the 26-item team-learning scale and includes the developmentoriented configuration $(\beta=0.533 ; P=0.000)$ and teamlearning environment $(\beta=0.408 ; P=0.000)$ variables. Its tolerance score is 0.312 , and its VIF score is 3.2. The commonality data in Table 4 indicate that the regression was influenced by interrelationships between the independent variables in this model: development-oriented configuration uniquely explained $10.9 \%$ of the regression effect (0.811). Team-learning environment explained $6.4 \%$ of the regression effect. Common variance between the two predictor variables made up the remainder of the regression effect. These findings indicate that $82.6 \%$ of the regression effect was explained by the combination of the development-oriented configuration and the team-learning environment.

Model $3(P=0.009)$ explains $83 \%$ of the variance in the 26 -item team learning scale and contains the development-oriented configuration $(\beta=0.533 ; P=0.000)$, team-learning environment $(\beta=0.408 ; P=0.000)$, and the regulation-oriented configuration $(\beta=0.177 ; P=0.009)$ variables, which were independent variables. The commonality matrix in Table 5 shows the unique contribution to the regression effect $\left(\% R^{2}\right)$ of the development-oriented configuration variable is $3.9 \%$. The unique contribution to the $\% R^{2}$ of team-learning environment is $7.2 \%$. The unique contribution to the $\% R^{2}$ of regulation-oriented configuration is $2 \%$. The combination of the independent variables in this model explains $88.9 \%$ of the total regression effect $\left(\% R^{2}\right)$ on team learning. The combination of the team-learning environment and development-oriented configuration accounts for $36.5 \%$ of the regression effect. The combination of the independent variables (team-learning environment, development-oriented configuration, and regulation-oriented configuration) accounts for $44.4 \%$ of the regression effect. The commonality tables for models 2 and 3 are available from the authors upon request. 
Table 3 Summary results and relationships between team-learning (dependent) and contextual factors using regression analyses

\begin{tabular}{|c|c|c|c|c|c|c|c|c|}
\hline Univariate regression analyses & $r^{2}$ & B & $\beta$ & $P$ & & & & \\
\hline Team-learning environment & 0.722 & 2.302 & 0.850 & 0.000 & & & & \\
\hline Regulation-oriented configuration & 0.433 & 37.448 & 0.658 & 0.000 & & & & \\
\hline Goal-oriented configuration & 0.475 & 23.440 & 0.690 & 0.001 & & & & \\
\hline Team-oriented configuration & 0.762 & 13.196 & 0.852 & 0.007 & & & & \\
\hline Development-oriented configuration & 0.759 & 14.507 & 0.871 & 0.001 & & & & \\
\hline $\begin{array}{l}\text { Multiple regression analyses } \\
\text { (stepwise) }\end{array}$ & Mult. $R^{2}$ & B & $\beta$ & $P$ & Unique & Common & Total $\left(r^{2}\right)$ & $\%$ Mult. $\mathbf{R}^{2}\left(r_{s}^{2}\right)$ \\
\hline Model I (Constant) & & 14.507 & & 0.001 & & & & \\
\hline \multicolumn{9}{|l|}{ configuration } \\
\hline & 0.759 & & & & & & & \\
\hline Model 2 (constant) & & 11.184 & & 0.005 & & & & \\
\hline $\begin{array}{l}\text { Development-oriented } \\
\text { configuration }\end{array}$ & & 2.062 & 0.533 & 0.000 & 0.089 & 0.670 & 0.759 & 0.936 \\
\hline $\begin{array}{l}\text { configuration } \\
\text { Team-learning environment }\end{array}$ & 0.811 & 0.720 & 0.408 & 0.000 & 0.052 & 0.670 & 0.722 & 0.890 \\
\hline Model 3 (constant) & & 8.281 & & 0.037 & & & & \\
\hline $\begin{array}{l}\text { Development-oriented } \\
\text { configuration }\end{array}$ & & 1.489 & 0.533 & 0.000 & 0.0328 & 0.727 & 0.759 & 0.917 \\
\hline Team-learning environment & & $0.78 \mathrm{I}$ & 0.408 & 0.000 & 0.0596 & 0.663 & 0.722 & 0.872 \\
\hline Regulation-oriented configuration & & 0.607 & 0.177 & 0.009 & 0.0167 & 0.416 & 0.433 & 0.523 \\
\hline & 0.828 & & & & & & & \\
\hline
\end{tabular}

Notes: Unique = x's unique effect; Common $=\Sigma x$ 's common effects; Total $=$ Unique + Common; $\%$ of $R^{2}=$ Total $/ R^{2}$.

\section{Discussion}

The aim of this study was to study the relationship between team learning and the team-learning environment and configuration of organization characteristics of the nursing team. Conventional organizational learning literature describes production-oriented and development-oriented team learning in teams, but reports an inability to exploit both learning processes simultaneously. ${ }^{11,30}$ Nonetheless, the results of this study underline modern theoretical insights on ambidexterity in nursing teams by revealing the simultaneous prevalence of production- and development-oriented team learning processes in nursing teams. ${ }^{8,10,11}$ The conventional theories on learning in teams and organizations were created in an era when teams acted in a stable context in which changes and

Table 4 Commonality matrix regression model 2

\begin{tabular}{lll}
\hline Variables & Coefficient & $\%$ of $R^{2}$ \\
\hline $\begin{array}{l}\text { Unique to development-oriented } \\
\text { configuration }\end{array}$ & 0.089 & 10.9 \\
$\begin{array}{l}\text { Unique to team-learning environment } \\
\text { Common to development-oriented }\end{array}$ & 0.052 & 6.4 \\
$\begin{array}{l}\text { configuration and team-learning } \\
\text { environment }\end{array}$ & 0.670 & 82.6 \\
\begin{tabular}{l} 
Total \\
\hline
\end{tabular} & 0.811 & \\
\hline
\end{tabular}

Notes: Coefficient $=$ variables unique regression effect; $\%$ of $R^{2}=$ percent of total explained variance. innovation were rare. ${ }^{31}$ In contrast, the current context of nursing is characterized by an overload of operational pressure and constantly changing practices. ${ }^{6,32}$ Nowadays, nursing teams are forced to exploit ambidextrous team learning processes. ${ }^{5,7,9}$

The existence of ambidextrous team-learning processes related positively to a supportive context in which individual team

Table 5 Commonality matrix regression model 3

\begin{tabular}{lll}
\hline Variables & Coefficient & $\%$ of $\boldsymbol{R}^{\mathbf{2}}$ \\
\hline $\begin{array}{l}\text { Unique to development-oriented } \\
\text { configuration }\end{array}$ & 0.033 & 3.9 \\
$\begin{array}{l}\text { Unique to team-learning environment } \\
\text { Unique to regulation-oriented }\end{array}$ & 0.060 & 7.2 \\
$\begin{array}{l}\text { configuration } \\
\text { Common to development-oriented }\end{array}$ & 0.017 & 2.0 \\
$\begin{array}{l}\text { configuration and team-learning } \\
\text { environment }\end{array}$ & 0.303 & 36.5 \\
$\begin{array}{l}\text { Common to development-oriented } \\
\text { configuration and regulation-oriented } \\
\text { configuration }\end{array}$ & 0.056 & 6.7 \\
$\begin{array}{l}\text { Common to team-learning environment } \\
\text { and regulation-oriented configuration }\end{array}$ & -0.008 & -0.9 \\
$\begin{array}{l}\text { Common to development-oriented } \\
\text { configuration, team-learning environment, } \\
\text { and regulation-oriented configuration }\end{array}$ & 0.368 & 44.4 \\
$\begin{array}{l}\text { Total } \\
\text { Notes: Coefficient = variables unique regression effect; \% of } R^{2}=\text { percent of total } \\
\text { explained variance. }\end{array}$ & & \\
\hline
\end{tabular}


members modify their behavior as well as question and modify the underlying values, assumptions, and policies that led to the behavior in the first place. ${ }^{15,33}$ Regression effects in this study were not caused by the unique contribution of the independent contextual factors, but by the commonality of their concurrent prevalence. This underlines context as a multifactorial construct wherein the independent factors interrelate and create a specific configuration that hinders or facilitates team learning. ${ }^{32,34}$ Van Wetten et $\mathrm{al}^{20}$ and Edmondson ${ }^{34}$ identified the team-learning environment as one of the most important contextual factors for team learning. ${ }^{20,34}$ Still, we expected a stronger impact from the team-learning environment. Team-learning environment items such as "safety" and "shared goals" facilitated team learning, but above all, the results in this study highlighted the commonality with other contextual factors such as the development-oriented and regulation-oriented team configuration relationships.

In accordance with Edmondson et al, ${ }^{16}$ we detected relationships between team learning and a context with development-oriented organizational characteristics. ${ }^{35,36}$ In this type of configuration, teams gather and process information on important developments outside the team and actively cross the boundaries of their own teams and professions. ${ }^{7,18}$ In line with the first hypothesis in this study, team learning was positively associated with the team-learning environment, the team-oriented configuration, and the development-oriented team configuration. ${ }^{7,16}$ In contrast to the second hypothesis, the results of this study also revealed a positive relationship between team learning and the regulation-oriented configuration on team learning. In accordance with the theoretical statements of Homan and Radstake ${ }^{35}$ and Edmondson et al, ${ }^{16}$ team learning in a nursing team requires regulation of the team learning processes, described as structured, regular team meetings with the goal of enhancing team learning. ${ }^{16,35}$ An infrastructure in the nursing team often exists to handle production-oriented learning tasks. Examples include the handover, daily meetings, and team meetings where information about production is shared, processed, and stored in minutes or patient records. Infrastructures for handling development oriented learning tasks are rare in nursing teams. Up and coming examples are initiatives such as journal clubs and evidence-based nursing meetings in nursing teams. These meetings are structured, regular meetings designed to facilitate developmental learning in the nursing team. Initiatives such as journal clubs only succeed if there is a supportive infrastructure on the ward that is visible as planned, regular meetings dedicated to the journal club. ${ }^{36}$

In conclusion, team learning in nursing teams was positively associated with a combination of contextual factors: team-learning environment, development-oriented team configuration, and regulation-oriented team configuration. Although the contextual factors can be divided into separate theoretical constructs, in reality, these factors exist in a configuration of independent contextual factors. This study has two important implications for practice. First, transferring the literature on team learning and ambidexterity to nursing teams reveals how nursing teams learn in modern times. Nurses in teams simultaneously undertake various team-learning activities to process the production-oriented and development-oriented information. Second, linking team learning and context revealed the insights in the commonality of contextual factors in nursing teams. This study underlines the importance of building a supportive context for team learning in nursing teams.

\section{Limitations}

In this study, we used questionnaires to capture responders' perceptions of both team-learning activities and contextual factors in their nursing teams. These perception based data could cause several limitations of this study when aggregated to team level data. ${ }^{25,26}$ The effective sample size was limited to 79 nursing teams. In addition, measurements could be influenced by tendentious perceptions of individual responders, which would also affect the aggregated scores. Statistical procedures, however, showed satisfactory scores on the assumptions for aggregation. ${ }^{25}$ Also, the concepts in this study were formulated clearly at the team level. ${ }^{7}$ In the regression analyses, team learning was analyzed with the overall 26-item scale, which limited information on the five different teamlearning factors. Consequently, analyses of the relationships between the five factors of team learning and the contextual factors were only provided as correlations.

\section{Issues for further research}

We suggest that future research uses more longitudinal designs to study team learning in relation to context over time. In addition, we suggest further research to include more in-depth analyses on the level of the five subscales of team learning. In terms of future research, one of the most interesting questions is the assumed relationship between ambidextrous team learning and the implementation of innovations in nursing teams. Therefore, we suggest studying the relationship between the five team learning factors and the implementation effect of different types of innovations in nursing teams.

\section{Disclosure}

The authors report no conflicts of interest in this work. 


\section{References}

1. Salas E, Cooke NJ, Rosen MA. On teams, teamwork, and team performance: discoveries and developments. Hum Factors. 2008;50(3):540-547.

2. Van Achterberg T, Schoonhoven L, Grol R. Nursing implementation science: how evidence-based nursing requires evidence-based implementation. J Nurs Sch. 2008;40(4):302-310.

3. Berta W, Teare GF, Gilbart E. et al. The contingencies of organizational learning in long-term care: factors that affect innovation adoption. Health Care Manage Rev. 2005;30(4):282-292.

4. Lemieux-Charles L, McGuire WL. What do we know about health care team effectiveness? a review of the literature. Med Care Res Rev. 2006; 63(3):263-300.

5. Carman JM, Shortell SM, Foster RW. et al. Keys for successful implementation of total quality management in hospitals. Health Care Manage Rev. 2010;35(4):283-293.

6. Blakeney B, McCarthy C, Coakley E. Unlocking the power of innovation. Online J Issues Nurs. 2009;14(2). doi: 10.3912/OJIN. VO114No02Man01.

7. Van Linge R. Innoveren in de gezondheidszorg, theorie, praktijk en onderzoek (Innovation in health care, theory, practice and research). Maarssen, the Netherlands; Elsevier Gezondheidszorg; 2006.

8. Raisch S, Birkinshaw J. Organizational ambidexterity: antecedents, outcomes, and moderators. J Manage. 2008;34(3):375-409.

9. Holleman G, Poot E, Mintjes-de Groot J, Van Achterberg T. The relevance of team characteristics and team directed strategies in the implementation of nursing innovations: A literature review. Int J Nurs Stud. 2009;46(9):1256-1264.

10. Timmermans O, Van Linge R, Van Petegem P, Elseviers M, Denekens J. Team learning and team composition in Nursing. The Journal of Workplace Learning. 2011;23(4):258-275.

11. Kang SC, Snell SA. Intellectual capital architectures and ambidextrous learning: a framework for human resource management. Journal of Management Studies. 2009;46(1):65-92.

12. Sessa VL, London M. Work Group Learning: Understanding, Improving and Assessing how Groups Learn in Organizations. New York: Lawrence Erlbaum Associates; 2007.

13. Miller DA. A preliminary typology of organizational learning: synthesizing the literature. J Manage. 1996;22(3):485-505.

14. Erdem M. Effects of learning style profile of team on quality of materials developed in collaborative learning processes. Active Learning in Higher Education. 2009;10(2):154-171.

15. Argyris C. On Organizational Learning. Oxford, UK: Blackwell Publishing; 1999.

16. Edmondson AC, Dillon JR, Roloff KS. Chapter 6: Three Perspectives on Team Learning - Outcome Improvement, Task Mastery, and Group Process. Acad Manag Ann. 2007;1(1):269-314.

17. Heinemann GD, Zeiss AM. Team performance in health care: assessment and development. 1st ed. New York: Kluwer Academic/ Plenum Publishers; 2002.
18. Edmondson AC, Bohmer RM, Pisano GP. Disrupted routines: team learning and new technology implementation in hospitals. Adm Sci $Q$. 2001;46(4):685-716.

19. Bennett J. The relationship between team and organisational learning. Int J Health Care Qual Assur. 2001;14(1):14-21.

20. Van Wetten H, Kok I, Wagner CG. [Measurement of Outcomes in Mental Health Care; study of implementation in mental health organizations]. Utrecht, the Netherlands: Nivell; 2005. Dutch.

21. Scheinn EH. Organizational culture and leadership. San Fransisco, CA: Jossey-Bass; 1992.

22. Quinn RE, Cameron K. Organizational life cycles and shifting criteria of effectiveness: some preliminary evidence. Manage Sci. 1983;29(1): 33-51.

23. Fox-Wasylyshyn SM, El-Masri MM. Handling missing data in self-report measures. Res Nurs Health. 2005;28(6):488-495.

24. Polit DF, Beck CT. Nursing Research: Principles and Methods. 7th ed. Philadelphia, PA: Lippincott Williams and Wilkens; 2003.

25. Klein KJ, Kozlowski SWJ. From Micro to Meso: Critical Steps in Conceptualizing and Conducting Multilevel Research. Organizational Research Methods. 2000;3(3):211-236.

26. Van Woerkom M, Croon M. The relationships between team learning activities and team performance. Personnel Review. 2009;38(5):560-577.

27. Van Woerkom M, van Engen ML. Learning from conflicts? The relations between task and relationship conflicts, team learning and team performance. European Journal of Work and Organizational Psychology. 2009;18(4):381-404.

28. Bliese PD. Within-group agreement, non-independence, and reliability: Implications for data aggregation and analysis. In: Klein KJ, Kozlowski WJ, editors. Multilevel theory, research, and methods in organizations. San Francisco, CA: Jossey-Bass; 2000:349-381.

29. Nimon K, Lewis M, Kane R, Haynes RM. An R package to compute commonality coefficients in the multiple regression case: An introduction to the package and a practical example. Beha Res Methods. 2008; 40(2):457-466.

30. Argyris C. A life full of learning. Organization Studies. 2003;24(7): 1178-1192.

31. Nonaka I, Takeuchi H. The Knowledge Creating Company. New York: Oxford University Press; 1995.

32. Kalisch BJ, Lee H. Nursing teamwork, staff characteristics, work schedules, and staffing. Health Care Manage Rev 2009;34(4):323-333.

33. Illeris K. Contemporary theories of learning: Learning theorists ... in their own words. New York: Routledge; 2009.

34. Edmondson AC. Learning from failure in health care: frequent opportunities, pervasive barriers. Qual Saf Health Care. 2004;13(Suppl 2): ii3-ii9. doi: 10.1136/qshc.2003.009597.

35. Homan T, Radstake D. Teamleren, theorie en facilitatie [Team learning: Theory and Facilitation]. Schoonhoven, the Netherlands: Academic Service; 2001. Dutch.

36. Luby M, Riley JK, Towne G. Nursing research journal clubs: bridging the gap between practice and research. Medsurg Nurs. 2006;15(2): $100-102$.
Nursing: Research and Reviews

\section{Publish your work in this journal}

Nursing: Research and Reviews is an international, peer-reviewed, open access journal publishing original research, reports, reviews and commentaries on all aspects of nursing and patient care. These include patient education and counselling, ethics, management and organizational issues, diagnostics and prescribing, economics and

\section{Dovepress}

resource management, health outcomes, and improving patient safety in all settings. The manuscript management system is completely online and includes a very quick and fair peer-review system. Visit $\mathrm{http}: / /$ www.dovepress.com/testimonials.php to read real quotes from published authors. 